\title{
Transesophageal drainage of an infected broncho- genous cyst via endoscopic ultrasound-guided implantation of a 7-Fr nasocystic drainage catheter
}
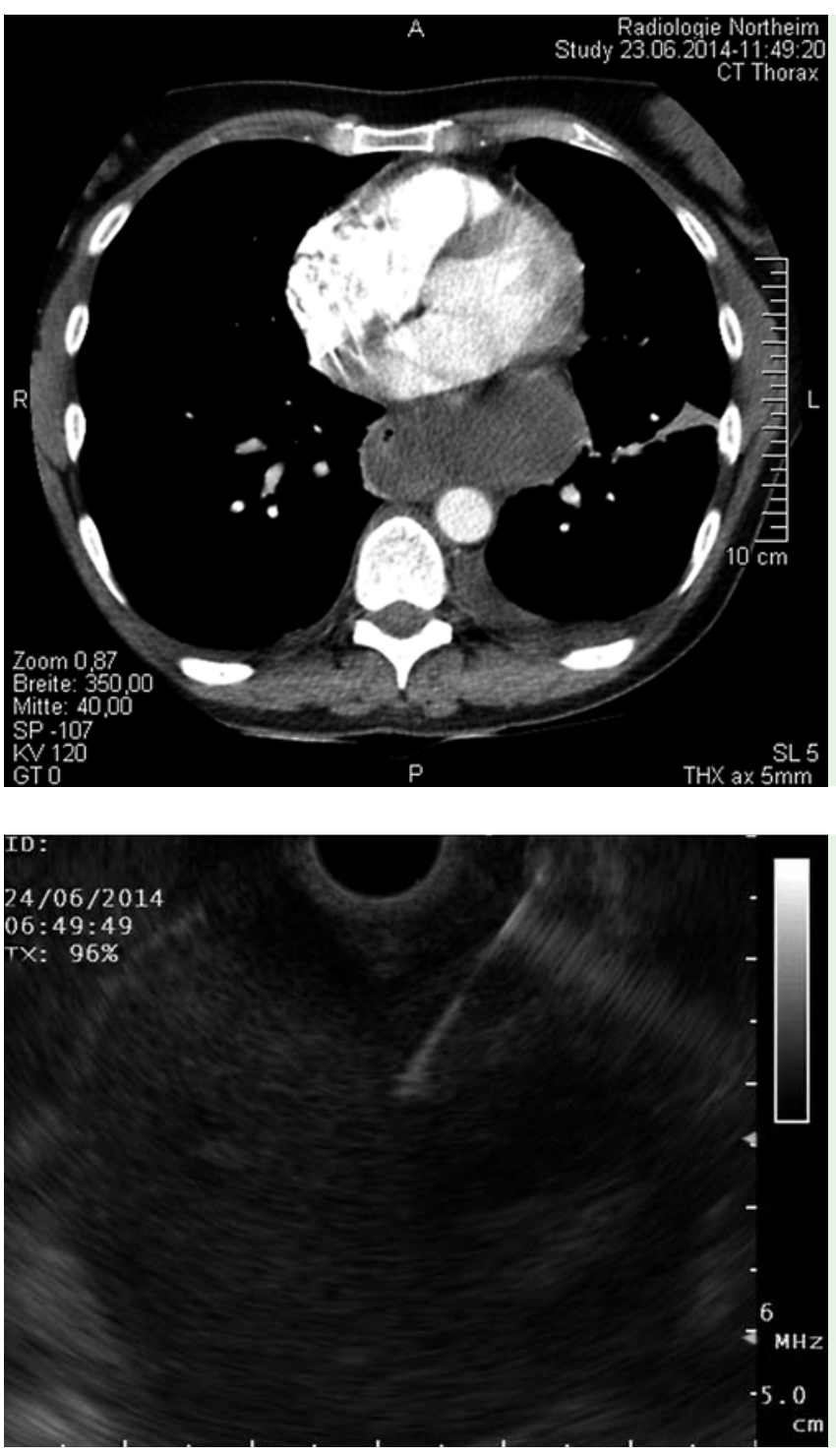

Fig. 1 Computed tomography (CT) scan in a 47-year-old woman with an asymptomatic bronchogenic cyst shows the cyst with dislocation and compression of the esophagus.

Fig. 3 Endoscopic ultrasound (EUS) appearance of the cyst with fine-needle aspiration in progress.

\section{A 47-year-old woman was admitted to} our emergency department with dysphagia and retrosternal pain. The patient's history revealed the existence of an asymptomatic bronchogenic cyst. Computed tomography (CT) demonstrated a cyst ( Fig. 1) which had compressed the esophagus and which was in close contact with the left atrium. Echocardiography showed an intact pericardium. Esophagoscopy showed the external compression of the esophagus by the lesion ( Fig.2). Endoscopic ultrasound (EUS) was performed, demonstrating a non-anechoic bronchogenic cyst ( $\bullet$ Fig.3). For diagnostic reasons, fine-needle aspiration was performed which revealed pus. We decided to switch to a conventional cystotome. Under EUS guidance, a 0.038-inch guidewire was introduced into the cyst and a 7-Fr nasocystic drainage catheter was applied ( Fig.4) and flushed with saline $0.9 \%$ solution every 4 hours. After 5 days, a further CT scan was performed ( $\bullet$ Fig.5), showing a slowly narrowing cyst. By then, the results of the resistogram had become available and showed Staphylococcus aureus resistant to ceftriaxone and meropenem, but sensitive to co-trimoxazole. After changing the

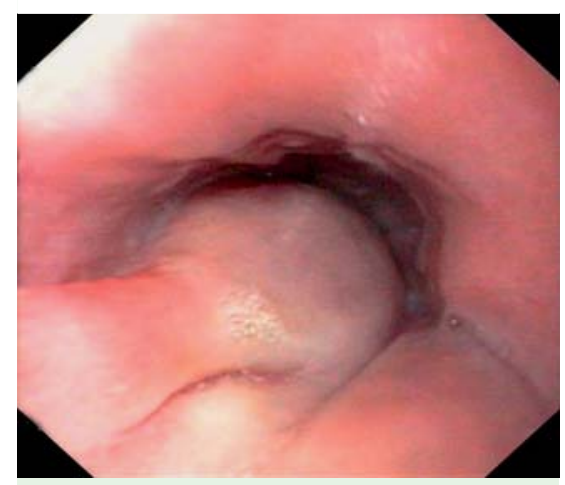

Fig.2 Esophagoscopy revealed external compression of the esophagus with stenosis.

antibiotic regimen, the cyst had almost disappeared after 11 days ( $\bullet$ Fig. 6 ) and the drainage was removed.

Usually, symptomatic bronchogenic cysts are treated by open or minimally invasive thoracic surgery [1]. In the case of asymptomatic cysts, the treatment strategy is "wait and see" or prophylactic resection, depending on the clinical situation [2]. The first and, to date, only published case with EUS-guided nasocystic drainage of an infected bronchogenic cyst was demonstrated by Mahady et al. [3] without the need for surgery afterwards. As in our case, the cyst did not relapse, probably because of the scarring inflammatory process. There is always a risk of cyst recurrence, thus, procedures such as the instillation of ethanol might be an option in the case of relapse [4].

Endoscopy_UCTN_Code_TTT_1AS_2AB

\section{Competing interests: None}

\section{Martin Floer ${ }^{1}$, Henning Dörner ${ }^{2}$, Tobias Meister ${ }^{1}$}

${ }^{1}$ Department of Gastroenterology, Academic Teaching Hospital of the University of Göttingen, Helios Albert-SchweitzerHospital Northeim, Northeim, Germany

2 Department of Radiology, Academic Teaching Hospital of the University of Göttingen, Helios Albert-Schweitzer-Hospital Northeim, Northeim, Germany 

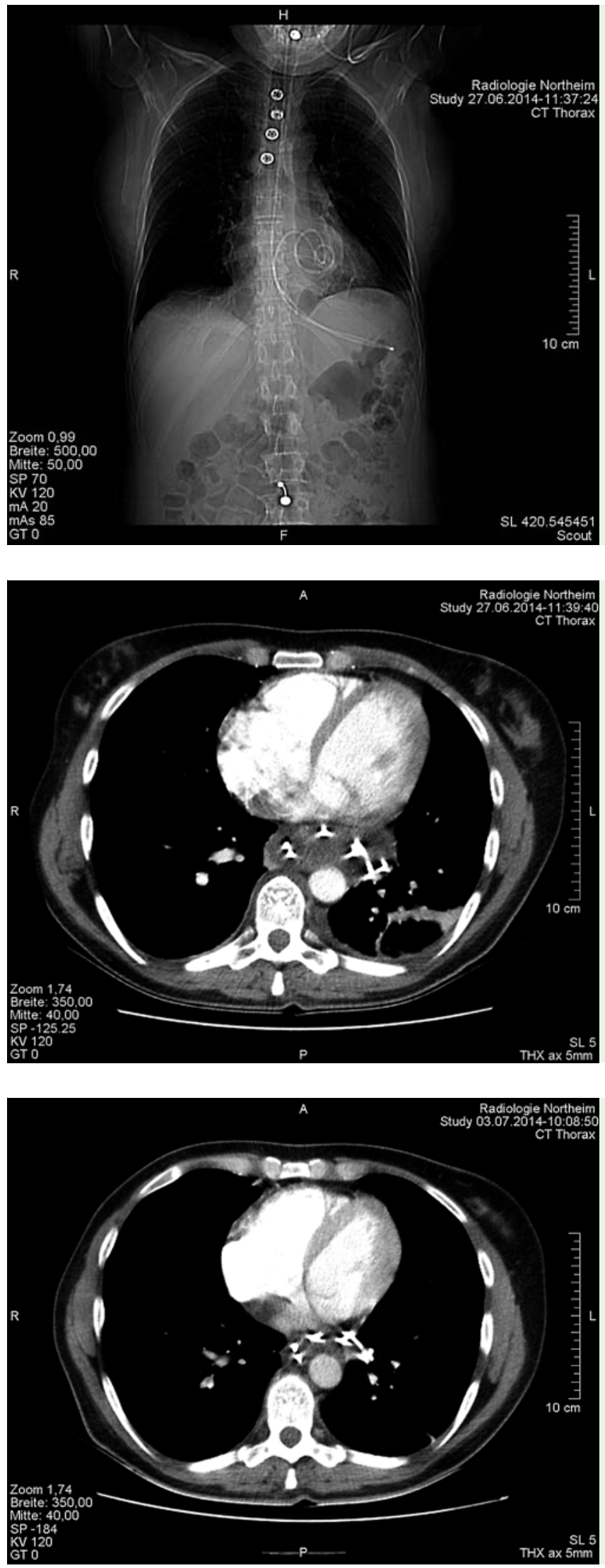

Fig. 4 CT Scout view demonstrates the position of the nasocystic drainage.

Fig. 5 CT scan 5 days after drainage showing a gradually narrowing cyst.

Fig. 6 Corresponding to $\bullet$ Fig. 5 , the CT scan 11 days after drainage showed that the cyst had almost completely disappeared.

\section{References}

1 Nobuhara KK, Gorski YC, La Quaglia MP et al. Bronchogenic cysts and esophageal duplications: common origins and treatment. J Pediatr Surg 1997; 32: 1408 - 1413

2 Michel JL, Revillon Y, Montupet P et al. Thoracoscopic treatment of mediastinal cysts in children. J Pediatr Surg 1998; 33: $1745-$ 1748

3 Mahady SE, Moss A, Kwan V. EUS-guided drainage of a mediastinal collection complicating FNA of a bronchogenic cyst. Gastrointest Endosc 2011; 73: 1306-1308

4 Lakadamyali $H$, Ergun T, Lakadamyali $H$. Alcohol ablation therapy of an atypically located symptomatic bronchogenic cyst: a case report. Cardiovasc Intervent Radiol 2007; 30: $1274-1276$

Bibliography

DOI http://dx.doi.org/

10.1055/s-0034-1390728

Endoscopy 2014; 46: E640-E641

(c) Georg Thieme Verlag KG

Stuttgart · New York

ISSN 0013-726X

\section{Corresponding author}

\section{Martin Floer, MD}

Department of Gastroenterology

Academic Teaching Hospital

of the University of Göttingen

Helios Albert-Schweitzer-Hospital Northeim

Strumbäume 8-10

37154 Northeim

Germany

Fax: +49-5551-971242

martin.floer@helios-kliniken.de 